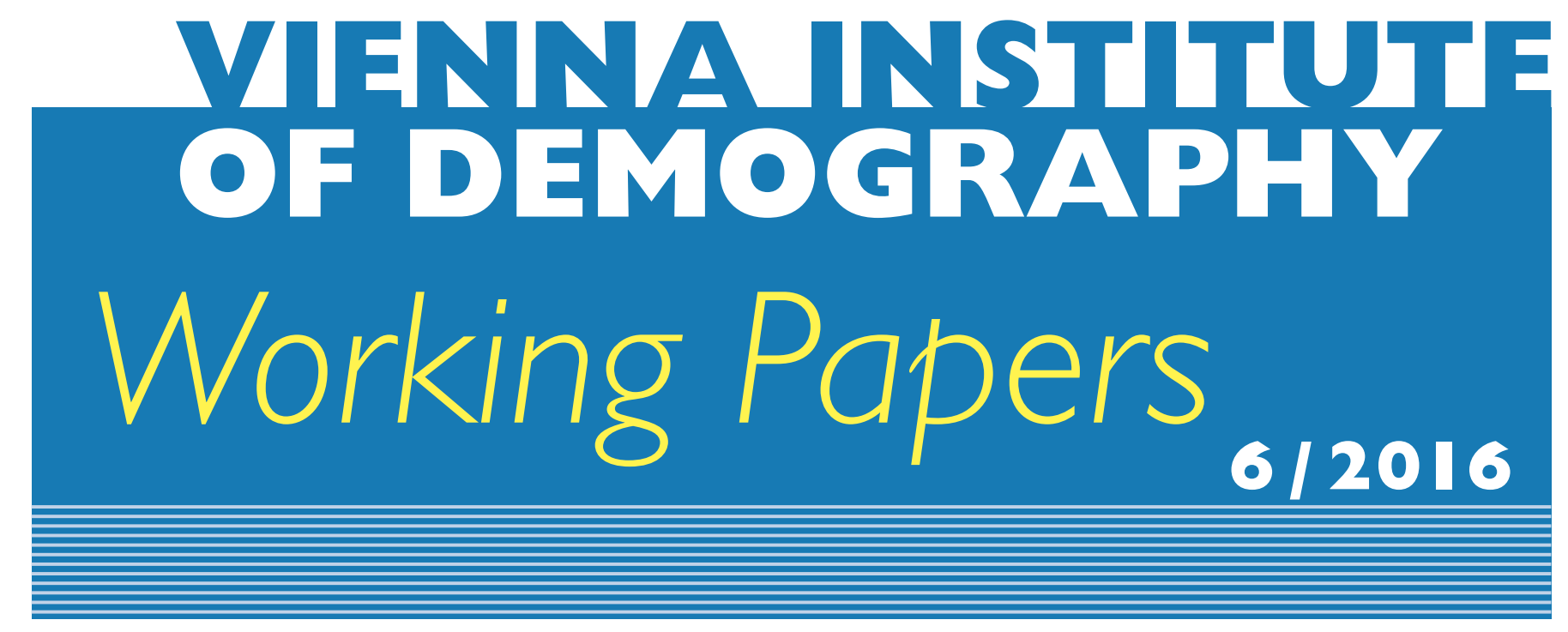

Judith Kohlenberger, Isabella Buber-Ennser, Bernhard Rengs and Zakarya Al Zalak

\title{
A Social Survey on Asylum Seekers in and around Vienna in Fall 2015: Methodological Approach and Field Observations
}

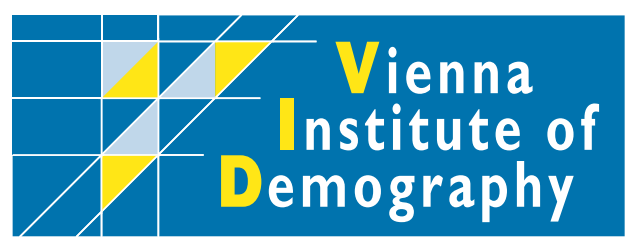

Vienna Institute of Demography Austrian Academy of Sciences

Welthandelsplatz 2 / Level 2

I020Vienna Austria

E-Mail:vid@oeaw.ac.at

Website: www.oeaw.ac.at/vid

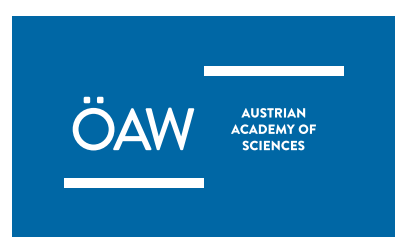




\begin{abstract}
In late 2015, a survey called DiPAS (Displaced persons in Austria survey) was carried out in and around Vienna to study the socio-demographic characteristics, values and attitudes of asylum seekers arriving in Austria in 2015. In that year, the number of persons seeking refuge in Europe was substantially high, with Austria being the fourth largest receiving country of asylum seekers in Europe. This data collection is the first of its kind in Austria and to our knowledge the first in Europe focusing on the recent arrivals of Syrian, Iraqi, and Afghan asylum seekers. First results on human capital and attitudes of DiPAS respondents have been published recently. The current paper presents the methodological approach of collecting these data, experiences from survey preparation, and insights from the field phase. Findings address four key challenges faced by surveys of the highly mobile and vulnerable group of asylum seekers, namely (1) representativity, (2) language barriers, (3) ethical considerations, and (4) cultural diversity. We discuss concrete solutions and recommendations for similar (inter)national, cross-cultural surveys, and provide insights for planning longitudinal studies on displaced persons who recently arrived in Europe.
\end{abstract}

\title{
Keywords
}

Refugees, asylum seekers, irregular migration, survey, Syria, Iraq, Afghanistan, methodology, field phase.

\section{Affiliations}

Judith Kohlenberger (corresponding author), Wittgenstein Centre (IIASA, VID/ÖAW, WU), Vienna University of Economics and Business.

Email: judith.kohlenberger@wu.ac.at

Isabella Buber-Ennser, Wittgenstein Centre (IIASA, VID/ÖAW, WU), Vienna Institute of Demography/Austrian Academy of Sciences. Email: isabella.buber@oeaw.ac.at

Bernhard Rengs, Wittgenstein Centre (IIASA, VID/ÖAW, WU), Vienna Institute of Demography/Austrian Academy of Sciences. Email: bernhard.rengs@oeaw.ac.at

Zakarya Al Zalak, Wittgenstein Centre (IIASA, VID/ÖAW, WU), International Institute for Applied Systems Analysis. Email: alzalak@iiasa.ac.at

\section{Acknowledgements}

This paper was partially funded by the Austrian Science Fund (FWF): Z171-G11. 


\title{
A Social Survey on Asylum Seekers in and around Vienna in Fall 2015: Methodological Approach and Field Observations
}

\author{
Judith Kohlenberger, Isabella Buber-Ennser, Bernhard Rengs and Zakarya Al Zalak
}

\section{Introduction}

Europe witnessed large inflows of displaced persons during the last years, especially due to violent conflicts in the Middle East and North Africa. In 2015, about one million individuals sought asylum in Europe, with Germany, Hungary, Sweden, Austria, Italy and France reporting highest inflows (Eurostat, 2016). Economic burdens for the receiving countries, implications for labor markets, welfare systems, social security and integration in the host countries are controversially discussed at political and societal levels, while individual data on these refugee populations are lacking (MacDonald, 2015).

Given the large number of asylum applications in Austria in fall 2015 (roughly 60,000 between July and December), we carried the so-called "Displaced Persons in Austria Survey (DiPAS)" in and around the Austrian capital Vienna to investigate socioeconomic characteristics, human capital and attitudes of refuge-seeking persons. To our knowledge, this survey is the first of its kind in the recent context, while several microdata collections are currently in preparation in Europe. First results on educational attainment, previous employment, self-assessed health, return intentions, future plans as well as attitudes and values on religiosity, religious tolerance, and gender equality of DiPAS respondents have been published recently (Buber-Ennser et al., 2016). In the current paper we present the methodological approach of DiPAS data collection, experiences from the preparation of this pioneering survey and from the field phase. In doing so, we aim to provide valuable insights for future surveys, especially in the current European context.

\section{Why study Asylum Seekers in Austria in Fall 2015?}

Although the majority of displaced persons arriving in 2015 in Austria travelled through the country on their way to Germany or Scandinavia, 88,098 individuals applied for asylum in Austria (BMI, 2016a), corresponding to about 1\% of the Austrian population. Three in four asylum seekers arriving in Austria in the course of 2015 were Afghan, Syrian or Iraqi citizens. Monthly statistics show that the fall of 2015 was the season with the highest number of asylum applications (Figure 1). 
Figure 1: Asylum Applications in Austria in 2014 and 2015

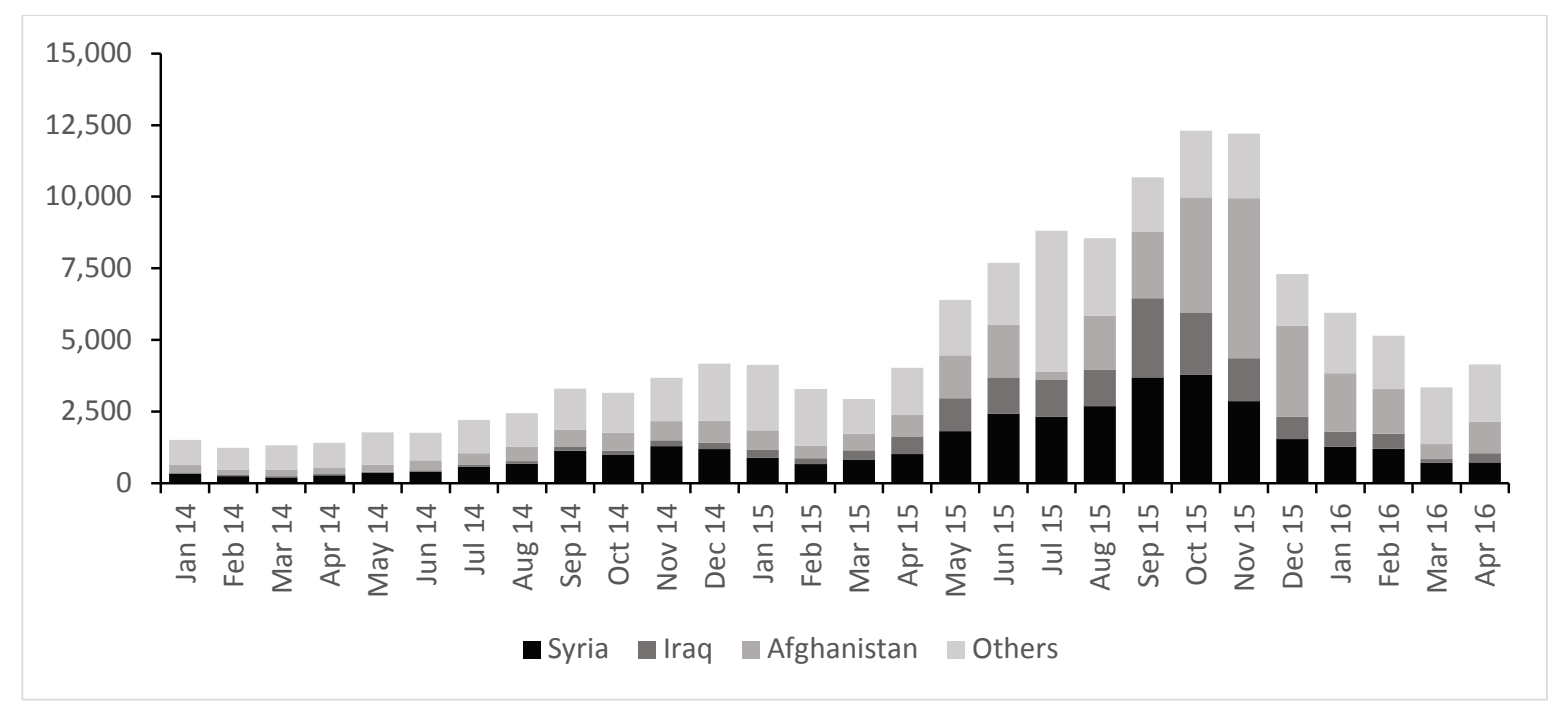

Sources: BMI (2015, 2016a, 2016b).

\section{Literature Review}

Asylum seekers and refugees are crucial in studies on forced migration, a research branch that focuses on displaced persons. Data on asylum seekers are typically collected by official institutions and government-related agencies and are usually restricted to basic information like number, sex, age and citizenship. Micro-level data are scarce, as only very few projects captured the characteristics of displaced persons arriving in Europe in the last years (Black et al., 2004; Brekke \& Aarset, 2009; OECD, 2016; Ruiz, Siegel, \& VargasSilva, 2015; Strand et al., 2008; UNHCR, 2015). Typically, researchers focus on one community or locality only and cooperation with and access through NGOs is common (Bloch, 2002; CHF International, 2012; Clark, 1992; Polzer Ngwato, 2013; Serrato, 2014; Singh \& Clark, 2013; UNHCR, 2015; Valenta, Zuparic-Iljic, \& Vidovic, 2015; Warfa et al., 2012). A noticeable exception is a representative survey among Palestinian refugee households in Lebanon (Ghattas, Sassine, Seyfert, Nord, \& Sahyoun, 2015; Habib, Hojeij, Elzein, Chaaban, \& Seyfert, 2014). Literature on displaced persons increasingly addresses ethical and methodological aspects of data collection (Bloch, 2004, 2007; Jacobsen \& Landau, 2003; McMichael, Nunn, Gifford, \& Correa-Velez, 2015). Broadly speaking, (1) representativity, (2) language, (3) ethical considerations as well as (4) cultural diversity are the main challenges.

Strategies of surveying immigrants in social surveys including a country's overall population have been addressed (Feskens, Hox, Lensvelt-Mulders, \& Schmeets, 2006; Font \& Méndez, 2013). Carrying out surveys among asylum seekers and refugees is even more challenging, as it is particularly difficult to generate representative samples of mobile populations (Bloch, 2007; Jacobsen \& Landau, 2003). Furthermore, displaced persons add the methodological challenge of being in a situation of emergency. They can be described 
as a rare or hidden group, whose members are hard to identify and locate for sampling (Faugier \& Sargeant, 1997; Kalton \& Anderson, 1986; Lee, 1993; UNHCR, 2013). To add, governments do not provide researchers with information to locate refugees for reasons of confidentiality (Bloch, 2004). Hence, Vigneswaran and Quirk go as far as concluding that "representativity is an unachievable ideal in survey research on refugee populations" (Vigneswaran \& Quirk, 2013, p. 110). Non-probability techniques are common and mostly rely on access through community-based organizations or NGOs (Bloch, 2007). Snowball sampling is frequently used, especially in qualitative research (e.g. Faugier \& Sargeant, 1997; Sulaiman-Hill \& Thompson, 2011). It has been argued that research on displaced persons always involves a degree of compromise (McMichael et al., 2015; Polzer Ngwato, 2013).

Addressing and adequately handling language barriers is generally relevant for survey participation, especially in cross-cultural studies and anthropology (Briggs, 1986; Chen, 2011; Winchatz, 2006), and achieves added significance in research on displaced persons with varying socio-cultural backgrounds and national heritages. Questionnaire translation is complex, because of linguistic and cultural variations (Warfa et al., 2012), as is the use of English as a lingua franca for communication with respondents with nonEnglish mother tongues. At the same time, the use of interpreters as mediators between researchers and respondents brings its own challenges (Naroll, 1962). Therefore, careful survey translation is crucial to data quality in multi-ethnic context (Harkness, Pennell, \& Schoua-Glusberg, 2004; Harkness, Van de Vijver, \& Mohler, 2003; Pasick, Stewart, Bird, \& D'Onofrio, 2001).

For research involving a population with a refugee-background, ethical considerations gain heightened relevancy (Block, Warr, Gibbs, \& Riggs, 2013; Chatty \& Marfleet, 2013). Experiences of trauma and insecurity during refugees' flight continue into the settlement context and may also affect refugees' willingness and ability to participate in research (UNHCR, 2013). Sensitive topics like recent deaths of family members or testimonies of war atrocities might cause data collection to be problematic for participants and interviewers (Decker, Naugle, Carter-Visscher, Bell, \& Seifert, 2011; Fahie, 2014; Renzetti \& Lee, 1993; Ruzek \& Zatzick, 2000; van der Velden, Bosmans, \& Scherpenzeel, 2013). Accordingly, the establishment of trust between the researcher and the researched is crucial (Hynes, 2003).

Finally, the aspect of cultural diversity, especially as far as it concerns researchers' and respondents' diverging cultural backgrounds, had to be addressed in the context of our survey, which involved researchers from mostly (Western) European descent and respondents with mostly Middle-Eastern background. Generally speaking, neither the one nor the other group constitutes a homogenous whole in today's super-diverse (Vertovec, 2007, 2009), cosmopolitan (Beck, 2004) or convivial (Gilroy, 2004) society. Therefore, cultural diversity is very much given from which follows that surveys are always carried out, to a certain degree, in a culturally diverse setting. The cultural heterogeneity of interviewers and interviewees must be recognized accordingly in order to guarantee that ethical considerations are adhered to and that adequate response rates can be achieved. In addition, and in line with the constructionist approach in contemporary cultural theory, an individual's cultural identity must be understood as fluid, subject to change and socially 
and historically contingent, rather than definite and coherent (Hall, 1992, 1997). This is especially true for groups with high mobility such as migrants and refugees, whose social, cultural and geographic circumstances are in constant fluctuation. In addition, and especially in recent years, one can discern a greater diversity within migrant groups (Font \& Méndez, 2013), particularly as concerns individuals' reasons for (forced) migration, socio-economic background and plans to return back to their home country. Font and Méndez note that "the list of potentially difficult themes is longer when we are talking about surveys addressed to immigrants" (p. 16), including sensitive aspects of respondents' actual circumstances (legal status, living situation, health, security concerns.). Ideally, these topics are negotiated in a continuous dialogue between researchers, interviewing staff and respondents (Myrberg, 2013) to allow for flexibility before, during and after the field phase.

\section{Methodological Approach and Reflections from the Field}

\subsection{Sample Design and Locations for Interviews}

DiPAS (Displaced Persons in Austria Survey) focused primarily on refuge-seeking persons from Syria, Iraq and Afghanistan, who constituted, as mentioned above, the largest share of asylum seekers in 2015. Minors below the age of 18, whether unaccompanied or not, were excluded from the survey.

The Austrian government allocated asylum seekers to various, mostly NGO-run emergency quarters in Austria. By the end of November 2015, one-third of forced migrants receiving basic assistance in Vienna were living in emergency quarters, the rest were living in smaller accommodations for displaced persons or in private homes. Given the high number of individuals who had to be accommodated within a short period of time, no distinction was made, neither by ethnicity, education nor other characteristics. This strategy turned out to be crucial for selecting respondents for surveying.

In order to sample displaced persons arriving in Austria in autumn 2015, we focused on large emergency quarters in and around Vienna, but also included smaller locations hosting asylum seekers. We conducted interviews in seven NGO-run locations, among them two large emergency quarters, which in November 2015 hosted about 900 and 400 persons respectively and five smaller buildings hosting less than 200 refuge-seeking persons at that time.

DiPAS is a two-stage purposely selected random sample. The first stage was the selection of accommodations, which was not random but reasoned purposely as mentioned above. The second stage was random. Within each accommodation, interviewers approached individuals and asked for participation. Additionally, we benefitted from indirect snowball effects, as those who gave an interview approached others within their accommodation and told them about the survey. For validation of the data and representativity, we refer to Buber-Ennser et al. (2016). Survey respondents did not receive incentives, but donations (mainly) in terms of food were given to the participating housing facilities. 
We carried out the survey over a condensed period of three weeks in November and December 2015. Our sample includes 514 adult respondents, residing in seven locations in and around Vienna and arriving in Austria in 2015. Another 22 interviews were started, but aborted by the respondents. Eight in ten respondents (82\%) arrived between September and November 2015, showing that the sample captures particularly those who arrived in autumn 2015. Detailed information on spouses and partners allows analyses of 977 refugeseeking persons living in Austria, and of further 419 partners and children abroad.

To validate the DiPAS sample for representativeness, it was compared to several statistics on the population of asylum seekers in Austria, in terms of numbers, age, and citizenship. Thereafter, the distribution by broad age groups of the 977 asylum-seeking individuals living in Austria captured in DiPAS is almost identical with that of all asylum seekers in 2015. Further specification by citizenship revealed that the age distribution of Iraqi citizens in the sample is almost identical with that of Iraqi asylum seekers arriving in Austria in 2015, and deviations in the age distribution by Syrians and Afghans are comparably small (Buber-Ennser et al., 2016). Due to lack of data on asylum seekers, bias regarding educational level, health or other individual characteristics cannot be explored.

\subsection{Questionnaire and Interviewers}

The questionnaire is mainly based on existing international surveys such as LFS (Labour Force Survey), EU-SILC (European Union Statistics on Income and Living Conditions), WVS (World Value Survey), SHARE (Survey of Health, Ageing and Retirement in Europe), GGS (Generations and Gender Survey), and EHIS (European Health Interview Survey), which allows the comparison of the DiPAS respondents with the general population in the countries of origin as well as with the Austrian population. Moreover, it includes questions regarding refugees' journeys and was approved by the Ethical Committee of the Austrian Academy of Sciences.

We implemented the survey as a CAPI (computer assisted personal interview) tool on touchscreen tablets. The original English questionnaire was translated into Arabic and Farsi/Dari and captures the following aspects: (1) Demography (age, gender, country of origin, marital status), (2) education, (3) former employment, (4) health, (5) information on spouse and children, (6) attitudes and norms (religion, democracy, gender equity), and (7) return intention and information on the route to Austria. In addition, background information on the interview situation was collected (e.g. interview language).

Interview staff consisted of Arabic, Farsi/Dari, Pashto or Kurdish native speakers, many with a refugee background, as well as students. Interviewers received extensive training, including intercultural competence. Even though the majority of the questionnaire consisted of questions taken from existing surveys, we conducted an intensive pre-test phase to test and adapt the questionnaire draft with regards to its suitability and comprehensibility in the specific context. 


\subsection{Reflections from the Field}

Our insights regarding language, ethical considerations on sensitive topics and cultural diversity stem from the preparation of the questionnaire, pre-tests, field phase and descriptive analyses.

To overcome the evident challenge of language, the English core questionnaire was translated into Arabic and Farsi/Dari. The former is the main language in Syria and Iraq, the latter is one of the two most commonly spoken languages in Afghanistan. Especially in Afghanistan, a variety of languages and idioms are spoken and restriction to Farsi/Dari implies a limitation of the study. Persons with other mother tongues were interviewed in English. Since the focus of our survey was firmly placed on refuge-seeking persons from the Arabic-speaking countries Syria and Iraq, the according restrictions in terms of possible interviewing languages and available interpreters seems justified. Software implementation was bilingual in English and Arabic, while Farsi/Dari interviews were assisted by hardcopies of English and Farsi/Dari questionnaires.

CAPI-Interviews were chiefly carried out in Arabic, Farsi/Dari and English. This strategy allowed to avoid a bias of attracting more highly educated respondents by offering the questionnaire exclusively in English or requiring basic literacy to read any information that could not be delivered orally.

Among the 514 interviews, two-thirds (67\%) were mainly carried out in Arabic, 20\% in Farsi/Dari, and $11 \%$ in English (Table 1). Although the majority of interviews conducted in Arabic and Farsi/Dari were held directly in the respondent's native language, the above numbers include interviews which were led by non-Arabic or Farsi/Dari speaking interviewers and interpreted or self-led by respondents through the translated versions of the questionnaire. A substantial number of interviews (37\%) was carried out by English- and native-speaking interviewers or interpreters together, while the majority was directly led in native language (51\%) (see Appendix).

Table 1: Main language of interview by citizenship

\begin{tabular}{lrrrrrr}
\hline & Arabic & $\begin{array}{r}\text { Farsi/Da } \\
\text { ri }\end{array}$ & English & Other & Total & Total(N \\
& & & & & ) \\
\hline Iraq & $34 \%$ & $0 \%$ & $3 \%$ & $1 \%$ & $38 \%$ & 196 \\
Syria & $31 \%$ & $0 \%$ & $4 \%$ & $1 \%$ & $36 \%$ & 184 \\
Afghanistan & $<1 \%$ & $14 \%$ & $2 \%$ & $<1 \%$ & $16 \%$ & 83 \\
Other & $2 \%$ & $6 \%$ & $2 \%$ & $<1 \%$ & $10 \%$ & 51 \\
\hline \multicolumn{1}{c}{ Total } & $67 \%$ & $20 \%$ & $11 \%$ & $2 \%$ & $100 \%$ & 514 \\
\hline
\end{tabular}

Source: DiPAS, $\mathrm{N}=514$ persons.

Note: Due to rounding, percentages may not add up to $100 \%$.

Collecting information on sensitive topics in a responsible way was key throughout the survey. Given the focus on human capital and socio-demographic characteristics, we only marginally touched upon traumatic experiences like the recent loss of family members, experience of persecution or torture. Nevertheless, for main demographic characteristics 
like marital status or number of children, one needs to expect cases of deceased partners and children. The recent loss of a close family member was captured without asking further details. In fact, how to ask for deceased family members was an important aspect of interviewer training. To increase interviewers' awareness for potentially traumatic topics and to ensure that they felt confident to handle the situation with the utmost sensitivity, our staff was carefully trained on how to react in case of emotionally intense reactions by respondents and learned a range of standard interviewing techniques for reacting appropriately and respectfully. After the field phase, interviewers were offered a psychological supervision meeting with a clinical psychologist to reflect on possible sensitive topics and situations, in line with previous research (Renzetti \& Lee, 1993).

In our sample, one in two interviewed adults had lost a family member since the situation in their country of origin forced them to flee. Loss of a family member was mentioned by 69\% of Afghans, by half of respondents from Syria and Iraq, and less often among individuals with another citizenship (19\%). Among our interviewees 13\% had lost a parent, $15 \%$ a sibling, $3 \%$ experienced the loss of husband, wife or children, and $26 \%$ reported the loss of other family members.

Asking religious affiliation turned out to be another sensitive topic, especially when native speakers participated in interviews. The first version of the questionnaire included detailed categories for Muslim sects like Sunni, Alawi, Ismaili, Shia or Druze. These distinctions were dropped after the pre-test phase due to ethical concerns. As the civil war in Syria has a major religious component, inquiring into respondents' specific religious affiliations inspired feelings of distrust; it seemed to lead respondents to question both their and the interviewer's affiliation and made them concerned about stereotypes associated with each group. Whereas asking for broad religious groups did not involve problems, we hence dropped the sensitive question for Muslim subgroups. Equally, the concept of asking for the degree of religiosity turned out to be confusing and strange for some interviewees. They argued that religiosity cannot be measured on a scale from zero to ten (as included in the DiPAS questionnaire, based on WVS; see Appendix).

The third sensitive topic we want to highlight is trust. While the purely scientific purpose of our survey and its independence from asylum applications were stressed, the issue of trust still arose. Due to the limited space in some NGO accommodations, four in ten interviews (41\%) were carried out in rooms with multiple interviews at one time. Several respondents preferred not to be interviewed in the designated interview rooms due to an apparent fear of surveillance by technical equipment or general lack of privacy. Thus, respondents that wished were interviewed in their living quarters, typically in their living room. This interview situation accounted for a share of 36\%. The remaining interviews were carried out in separate but not personal rooms with only one interview at the same time $(7 \%)$, or in common rooms with other people around (16\%), who might have been in hearing range.

Our insights regarding cultural diversity relate to education, employment, and respondents' gender. Due to destroyed school buildings or displacement inside or outside the home country, enrolment of children in schools is low (Sirin \& Rogers-Sirin, 2015) and pursuing any form of education is difficult. For the current study, we adapted ISCED 
(International Standard Classification of Education) to measure educational levels by further splitting up ISCED 1 and aggregating ISCED 4 and 5. The following categories were coded: (1) No formal education (never been to school), (2) some primary (elementary) education, (3) completed primary (6 years), (4) completed lower secondary (9 years), (5) completed upper secondary (12 years), (6) bachelor or college and (7) master and more (see Appendix).

For previous employment in the home country, we used ISCO codes to allow comparison. In addition, we asked for short job descriptions, since jobs specific to the region of origin were difficult to code in ISCO, like shisha factory owner or carpet weaver. The classification of economic activities via NACE turned out to be applicable without adaptations.

Transferability of concepts was challenging regarding the extent of employment. Our pre-tests revealed that part of the respondents were not familiar with the standard Western distinction of work between part time and full time. Syrian respondents in particular seemed to subscribe to a model of "working on demand" and did not distinguish between working on weekdays as opposed to weekends. To accommodate this cultural difference between the Austrian labour system and the Middle Eastern one, the questionnaire included the number of working days per week or seasonal work in addition to working hours per week, in line with the Syrian manpower survey 2010 (Syrian Central Bureau of Statistics, 2016).

In the pre-tests, the cultural context of patriarchy became evident, as among couples it was typically the male partner who answered the questions. To account for this gender bias, we adapted the questionnaire to include detailed information on partners, enabling us to analyse education and previous work experiences of both partners. Therefore, DiPAS can be characterised as a household survey, with a preponderance of male respondents (82\%), as women often referred to their husbands. Whereas this is less problematic for analysing households and the family context, insights on attitudes of women are limited.

Regarding attitudes, we included questions about gender relations and household decision-making, taken from WVS and EU-SILC. Although initially much longer, this part was considerably shortened after pre-tests, because interviewees seemed slightly irritated by a large number of questions on attitudes (including controversial aspects like homosexuality, pre-marital sexual intercourse, abortion and contraception for single women), and because the survey's focus was on human capital. Additionally, certain concepts proved to be difficult to transfer or translate, for instance a question about the necessity for women to wear a headscarf in public. Finally, it was for the simple reasons of time and space that several questions on attitudes were dropped as redundant and not significant after the initial pre-tests.

Cultural factors furthermore influenced the planned interview flow. In pre-tests we employed the social survey standard practice to ask adult respondents for the number of their children regardless of their family status, which proved to be a sensitive issue. Some respondents who had stated that they were never married seemed to be irritated to be asked 
for the number of children. Native speaking interviewers were similarly reluctant to ask this question to never married respondents. As a result we adapted the interview flow.

As mentioned earlier, intercultural competence training was provided to the interviewers to compensate for diverging cultural backgrounds between the interviewers and respondents. Moreover, our survey allowed to answer sensitive questions in an anonymous way by self-completing individual questions on the touchscreen. The lessons learned from the pre-tests and the resulting adaptions of the questionnaire proved to be effective as few interviews were stopped prematurely and item non-response was low.

Finally, we provide insights valuable for longitudinal studies regarding refugee populations. Almost all respondents (99\%) were willing to be contacted again for followup interviews while fewer, but still a vast majority (89\%), were willing and able to give private contact details (telephone number, e-mail or Facebook contact). In March and April 2016, the latter were contacted to determine attrition and explore possibilities for longitudinal studies. It turned out that successful follow-up depended substantially on the type of contact given: Whereas six in ten Arabic speaking respondents who provided an Austrian telephone number were successfully contacted, the share was substantially lower when a foreign telephone number (27\%) or an email (12\%) was provided (see Appendix). Respondents providing phone numbers were contacted through multiple channels, via direct phone calls and multiple messaging services that use the telephone number as an identifier. The latter (e.g. Whatsapp, Viber, Telegram) are very popular in refugee communities to stay in contact with family and friends (Maitland \& Xu, 2015; Wall, Otis Campbell, \& Janbek, 2015). Facebook ID or name proved to be impractical for contacting interviewees again as these were often not unique identifiers. In the pilot project, these persons were not contacted due to limited resources.

Differences by citizenship became evident, as successful follow-up contact using phone numbers was substantially higher among Arabic-speaking respondents than Farsi/Dari-speaking ones. Moreover, Afghans were far less willing to share any contact information (see Appendix). Our tentative conclusion is that longitudinal studies among Afghan asylum seekers will likely face higher attrition than surveys among individuals from Syria or Iraq. To add, when planning and conceptualising longitudinal studies on asylum seekers it should be kept in mind that attrition is embedded in the larger political

context of the host country: Certain nationalities are less likely to be granted refugee status or subsidiary protection. For the DiPAS sample this means that Afghans, who have a low probability of being granted asylum in Austria (BMI, 2016a), are more likely to drop out of a longitudinal sample.

\section{Discussion}

We provide methodological aspects from a pioneering survey among asylum seekers in Austria. Although restricted to displaced persons in and around the Austrian capital Vienna, the insights gained during the field phase are valuable to other social science disciplines and quantitative data collection among asylum seekers and refugees. To sample the vulnerable group of refuge-seeking persons, our strategy was to focus on respondents 
residing in large emergency quarters, providing access to a large number of potential respondents at a single site.

To overcome language barriers and avoid high nonresponse (Feskens et al., 2006; Harkness et al., 2003; Winchatz, 2006), we carried out the survey mainly in native languages. Initial challenges concerning the translation of specific concepts led to multiple adaptations of the original questionnaire. We feel confident that giving respondents the choice of answering questions in either their native language (if Arabic or Farsi/Darispeaking) or in English as their lingua franca contributed to a generally high contact rate and to low item non-response rates, as did the additional support by on-site interpreters.

Ethical considerations involved in surveys on vulnerable groups were addressed in several ways. The pre-test period was crucial to identify and adapt questions which proved too sensitive, controversial or otherwise difficult to ask or understand, as they could result in the refusal to answer individual questions or even to a premature stop of the interview (Decker et al., 2011; Fahie, 2014; Renzetti \& Lee, 1993; Ruzek \& Zatzick, 2000; van der Velden et al., 2013). Simplified, emotionally neutral questions, a safe environment during the interviews, and the option to answer personal or sensitive questions in an anonymous way (i.e. by self-completing) were key in the DiPAS survey.

Interviewers reported that respondents expressed their gratitude after the actual interview for having been given an opportunity to talk about their (former) lives, family ties and home country. Due to the focus of the survey on human capital and qualifications, respondents felt like they could highlight their personal and professional achievements and potential contributions to the host country, rather than their recent, often traumatic experiences of war, destitution, and flight. These observations might be related to results from Feskens et al. (2006), who examined nonresponse rates among ethnic minorities in social surveys. Dissecting nonresponse into noncontact, refusal and inability revealed that contact rates among ethnic minorities are lower, whereas cooperation rates are higher among ethnic minorities than among the native population.

Finally, when conceptualizing the survey and carrying out the field phase, we met several challenges due to cultural diversity. Our interpreters simultaneously functioned as bi-cultural aides with national, ethnic and cultural background similar to that of the respondents. Furthermore, the majority of our bi-cultural aides also had a refugee background and could thus relate to the respondents' experiences. In addition to the culturally diverse interviewing staff and the use of interpreters, the cross-cultural expertise of one researcher with Syrian background involved in the project was extremely valuable throughout the project.

Due to restrictions of time and resources, the DiPAS survey is not representative of all asylum seekers currently residing in Austria, or other European countries. By focusing on a group of refuge-seeking persons, the survey captures their specific situation shortly after arriving. Our findings contribute to enhancing knowledge on carrying out surveys among displaced persons, especially in the current European context. First insights gained from the field phase of our pioneering survey might be regarded as a small but important piece of a large puzzle on displaced persons in Europe in 2015. 


\section{References}

Beck, U. (2004). Der kosmopolitische Blick [The cosmopolitical view]. Frankfurt/Main: Suhrkamp.

Black, R., Koser, K., Munk, K., Atfield, G., D’Onofrio, L., \& Tiemoko, R. (2004). Understanding voluntary return. London: Home Office.

Bloch, A. (2002). The migration and settlement of refugees in Britain. Basingstoke: Palgrave.

Bloch, A. (2004). Survey research with refugees. Policy Studies, 25(2), 139-151. doi:10.1080/0144287042000262215

Bloch, A. (2007). Methodological challenges for national and multi-sited comparative survey research. Journal of Refugee Studies, 20(2), 230-247. doi:10.1093/jrs/fem002

Block, K., Warr, D., Gibbs, L., \& Riggs, E. (2013). Addressing ethical and methodological challenges in research with refugee-background young people: Reflections from the field. Journal of Refugee Studies, 26(1), 69-87. doi:10.1093/jrs/fes002

BMI. (2015). Asylstatistik Dezember 2014 [Asylum statistics December 2014]. Vienna: Austrian Federal Ministry of the Interior.

BMI. (2016a). Asylstatistik 2015 [Asylum statistics 2015]. Vienna: Austrian Federal Ministry of the Interior.

BMI. (2016b). Vorläufige Asylstatistik April 2016 [Preliminary asylum statistics April 2016]. Vienna: Austrian Federal Ministry of the Interior.

Brekke, J.-P., \& Aarset, M. F. (2009). Why Norway? Understanding asylum destinations. Oslo: Institute for Social Research.

Briggs, C. L. (1986). Learning how to ask: A sociolinguistic appraisal of the role of the interview in social science research. Cambridge: Cambridge University Press.

Buber-Ennser, I., Kohlenberger, J., Rengs, B., Al Zalak, Z., Goujon, A., Striessnig, E., Potančoková, M., Gisser, R., Testa, M. R., \& Lutz, W. (2016). Human Capital, Values, and Attitudes of Persons Seeking Refuge in Austria in 2015. PLoS ONE, 11(9), e0163481. doi:10.1371/journal.pone.0163481

Chatty, D., \& Marfleet, P. (2013). Conceptual problems in forced migration. Refugee Survey Quarterly. doi:10.1093/rsq/hdt008

Chen, S.-H. (2011). Power relations between the researcher and the researched: An analysis of native and nonnative ethnographic interviews. Field Methods, 23(2), 119135. doi:10.1177/1525822x10387575

CHF International. (2012). Syrian refugee crisis: Rapid assessment report. Retrieved from Amman, Jordan: http://www.globalcommunities.org/publications/2012-syrianrefugee-assessment.pdf

Clark, G. (1992). Refugees and the Greenwich labour market. London: Local Economy Policy Unit, South Bank Polytechnic.

Decker, S. E., Naugle, A. E., Carter-Visscher, R., Bell, K., \& Seifert, A. (2011). Ethical issues in research on sensitive topics: Participants' experiences of distress and benefit. Journal of Empirical Research on Human Research Ethics, 6(3), 55-64. doi:10.1525/jer.2011.6.3.55

Eurostat. (2016). Eurostat: Your key to European statistics Retrieved from

http://ec.europa.eu/eurostat/web/asylum-and-managedmigration/data/database. $\quad$ http://ec.europa.eu/eurostat/web/asylum-and-managedmigration/data/database 
Fahie, D. (2014). Doing sensitive research sensitively: Ethical and methodological issues in researching workplace bullying. International Journal of Qualitative Methods, 13(1), 19-36. doi:10.1177/160940691401300108

Faugier, J., \& Sargeant, M. (1997). Sampling hard to reach populations. Journal of Advanced Nursing, 26(4), 790-797. doi:10.1046/j.1365-2648.1997.00371.x

Feskens, R., Hox, J., Lensvelt-Mulders, G., \& Schmeets, H. (2006). Collecting data among ethnic minorities in an international perspective. Field Methods, 18(3), 284-304. doi:10.1177/1525822X06288756

Font, J., \& Méndez, M. (Eds.). (2013). Immigrant populations. Methodological challenges and research strategies. Amsterdam: Amsterdam University Press.

Ghattas, H., Sassine, A. J., Seyfert, K., Nord, M., \& Sahyoun, N. R. (2015). Prevalence and correlates of food insecurity among Palestinian refugees in Lebanon: Data from a household survey. PLOS ONE, 10(6), e0130724. doi:10.1371/journal.pone.0130724

Gilroy, P. (2004). After empire. Melancholia or convivial culture? Oxfordshire: Routledge.

Habib, R. R., Hojeij, S., Elzein, K., Chaaban, J., \& Seyfert, K. (2014). Associations between life conditions and multi-morbidity in marginalized populations: The case of Palestinian refugees. The European Journal of Public Health, 24(5), 727-733. doi:10.1093/eurpub/cku089

Hall, S. (1992). The question of cultural identity. In S. Hall, D. Held, \& A. McGrew (Eds.), Modernity and its futures (pp. 274-316). Cambridge: Polity Press.

Hall, S. (1997). Representation: Cultural representations and signifying practices. London Thousand Oaks, California: Sage.

Harkness, J., Pennell, B.-E., \& Schoua-Glusberg, A. (2004). Survey questionnaire translation and assessment. In S. Presser, J. M. Rothgeb, M. P. Couper, J. T. Lessler, E. Martin, J. Martin, \& E. Singer (Eds.), Methods for testing and evaluating survey questionnaires (pp. 453-473). Hoboken, NJ: John Wiley.

Harkness, J., Van de Vijver, F. J. R., \& Mohler, P. P. (2003). Cross-cultural survey methods. Hoboken, N.J: John Wiley.

Hynes, P. (2003). The issue of "trust" or "mistrust" in research with refugees : Choices, caveats and considerations for researchers. Geneva: UNHCR.

Jacobsen, K., \& Landau, L. B. (2003). The dual imperative in refugee research: Some methodological and ethical considerations in social science research on forced migration. Disasters, 27(3), 185-206. doi:10.1111/1467-7717.00228

Kalton, G., \& Anderson, D. W. (1986). Sampling rare populations. Journal of the Royal Statistical Society. Series A (General), 149(1), 65-82. doi:10.2307/2981886

Lee, R. M. (1993). Doing research on sensitive topics. London: Sage.

MacDonald, A. (2015). Review of selected surveys of refugee populations, 2000-2014. Paper commissioned by the UNHCR. Paper presented at the International Conference on Refugee Statistics, 7-9 October 2015, Antalya, Turkey

Maitland, C., \& Xu, Y. (2015). A social informatics analysis of refugee mobile phone use: A case study of Za'atari Syrian refugee camp. Paper presented at the TPRC 43: The 43rd Research Conference on Communication, Information and Internet Policy Paper. http://dx.doi.org/10.2139/ssrn.2588300

McMichael, C., Nunn, C., Gifford, S. M., \& Correa-Velez, I. (2015). Studying refugee settlement through longitudinal research: Methodological and ethical insights from the Good Starts Study. Journal of Refugee Studies, 28(2), 238-257. doi:10.1093/jrs/feu017 
Myrberg, G. (2013). Surveying migrants and migrants' associations in Stockholm. In J. Font \& M. Méndez (Eds.), Surveying ethnic minorities and immigrant populations: Methodological challenges and research strategies (pp. 131-146). Amsterdam: Amsterdam University Press.

Naroll, R. (1962). Data quality control: A new research technique. New York: Free Press of Glencoe.

OECD. (2016). Making integration work: Refugees and others in need of protection. Retrieved from Paris: http://dx.doi.org/10.1787/9789264251236-en

Pasick, R. J., Stewart, S. L., Bird, J. A., \& D'Onofrio, C. N. (2001). Quality of data in multiethnic health surveys. Public Health Reports, 116(Suppl 1), 223-243. Retrieved from http://www.ncbi.nlm.nih.gov/pmc/articles/PMC1913670/

Polzer Ngwato, T. (2013). Collecting data on migrants through service provider NGOs: Towards data use and advocacy. Journal of Refugee Studies, 26(1), 144-154. doi:10.1093/jrs/fes034

Renzetti, C. M., \& Lee, R. M. (1993). Researching sensitive topics. Newbury Park, CA: Sage.

Ruiz, I., Siegel, M., \& Vargas-Silva, C. (2015). Forced up or down? The impact of forced migration on social status. Journal of Refugee Studies, 28(2), 183-201. doi:10.1093/jrs/feu035

Ruzek, J. I., \& Zatzick, D. F. (2000). Ethical considerations in research participation among acutely injured trauma survivors: An empirical investigation. General Hospital Psychiatry, 22(1), 27-36. doi:http://dx.doi.org/10.1016/S01638343(99)00041-9

Serrato, B. C. (2014). Refugee perceptions study. Za'atari camp and host communities in Jordan. Retrieved from Oxfam Research Reports, Oxford:

Singh, G., \& Clark, B. D. (2013). Creating a frame: A spatial approach to random sampling of immigrant households in inner city Johannesburg. Journal of Refugee Studies, 26(1), 126-144. doi:10.1093/jrs/fes031

Sirin, S., R., \& Rogers-Sirin, L. (2015). The educational and mental health needs of Syrian refugee children. Washington, DC: Migration Policy Institute.

Strand, A., Akbari, A., Wimpelmann Chaudhary, T., Berg Harpviken, K., Sarwari, A., \& Suhrke, A. (2008). Return in dignity, return to what? Review of the voluntary return programme to Afghanistan. Bergen: Christian Michelsen Institute.

Sulaiman-Hill, C., \& Thompson, S. C. (2011). Sampling challenges in a study examining refugee resettlement. BMC International Health and Human Rights, 11(1), 1-10. doi:10.1186/1472-698x-11-2

Syrian Central Bureau of Statistics. (2016). Manpower survey 2010. Retrieved from http://www.cbssyr.sy/work/2010/Questionnaire2010-semi2.htm

UNHCR. (2013). A new beginning: Refugee integration in Europe. Geneva: The UN Refugee Agency.

UNHCR. (2015). Syrian refugee arrivals in Greece, April - September 2015, preliminary questionnaire findings. Retrieved from Geneva:

Valenta, M., Zuparic-Iljic, D., \& Vidovic, T. (2015). The reluctant asylum-seekers: Migrants at the Southeastern frontiers of the European migration system. Refugee Survey Quarterly, hdv009.

van der Velden, P. G., Bosmans, M. W. G., \& Scherpenzeel, A. C. (2013). The burden of research on trauma for respondents: A prospective and comparative study on 
respondents evaluations and predictors. PLoS ONE, 8(10), e77266. doi:10.1371/journal.pone.0077266

Vertovec, S. (2007). Super-diversity and its implications. Ethnic and Racial Studies, 30(6), 1024-1054. doi:10.1080/01419870701599465

Vertovec, S. (2009). Transnationalism. London: Routledge.

Vigneswaran, D., \& Quirk, J. (2013). Quantitative methodological dilemmas in urban refugee research: A case study of Johannesburg. Journal of Refugee Studies, 26(1), 110-116. doi:10.1093/jrs/fes035

Wall, M., Otis Campbell, M., \& Janbek, D. (2015). Syrian refugees and information precarity. New Media \& Society. doi:10.1177/1461444815591967

Warfa, N., Curtis, S., Watters, C., Carswell, K., Ingleby, D., \& Bhui, K. (2012). Migration experiences, employment status and psychological distress among Somali immigrants: A mixed-method international study. BMC Public Health, 12(749), 112. doi:10.1186/1471-2458-12-749

Winchatz, M. R. (2006). Fieldworker or foreigner? Ethnographic interviewing in nonnative languages. Field Methods, 18(1), 83-97. doi:10.1177/1525822X05279902 


\section{Appendix}

Table I: Main language of interview and participation of language interpreters

\begin{tabular}{lrrrrrr}
\hline & Arabic & Farsi/Dari & English & Other & Total & Total (N) \\
\hline No interpreter & $44 \%$ & $7 \%$ & $10 \%$ & $2 \%$ & $63 \%$ & 322 \\
Arabic interpreter & $24 \%$ & $0 \%$ & $<1 \%$ & $<1 \%$ & $24 \%$ & 125 \\
Persian interpreter & $0 \%$ & $13 \%$ & $0 \%$ & $<1 \%$ & $13 \%$ & 67 \\
\hline Total & $67 \%$ & $20 \%$ & $11 \%$ & $2 \%$ & 100 & 514 \\
\end{tabular}

Source: DiPAS, $\mathrm{N}=514$ persons.

Remark: Due to rounding, percentages may not add up to $100 \%$.

Table II: Follow-up results of Arabic and Farsi/Dari speaking respondents

\begin{tabular}{lccccc}
\hline & Successful & $\begin{array}{c}\text { Not } \\
\text { successful }\end{array}$ & $\begin{array}{c}\text { Not } \\
\text { contacted }\end{array}$ & Total & \multirow{2}{*}{ Total (N) } \\
\hline Arabic speaking & & & & & \\
Austrian phone number & $57 \%$ & $40 \%$ & $4 \%$ & $100 \%$ & 159 \\
Foreign phone number & $27 \%$ & $68 \%$ & $5 \%$ & $100 \%$ & 44 \\
Email & $12 \%$ & $88 \%$ & $0 \%$ & $100 \%$ & 76 \\
Facebook or name only & $0 \%$ & $0 \%$ & $100 \%$ & $100 \%$ & 81 \\
\hline Total & $31 \%$ & $45 \%$ & $25 \%$ & $100 \%$ & 360 \\
\hline & & & & & \\
Farsi/Dari speaking & $40 \%$ & $57 \%$ & $3 \%$ & $100 \%$ & 62 \\
Austrian phone number & $(0 \%)$ & $(100 \%)$ & $(0 \%)$ & $100 \%$ & $(1)$ \\
Foreign phone number & $25 \%$ & $75 \%$ & $0 \%$ & $100 \%$ & 16 \\
Email & $0 \%$ & $0 \%$ & $100 \%$ & $100 \%$ & 12 \\
Facebook or name only & $32 \%$ & $53 \%$ & $15 \%$ & $100 \%$ & 91 \\
\hline \multicolumn{1}{c}{ Total } & & & & \\
\hline \multicolumn{2}{r}{ Sour Dipas, }
\end{tabular}

Source: DiPAS, $\mathrm{N}=451$ persons.

Remark: Due to rounding, percentages may not add up to $100 \%$.

Table III: Follow-up results and willingness to share contact information by country

\begin{tabular}{|c|c|c|c|c|c|c|}
\hline & Successful & $\begin{array}{l}\text { Not } \\
\text { successful }\end{array}$ & $\begin{array}{l}\text { Not } \\
\text { contacted }\end{array}$ & $\begin{array}{l}\text { No information Total } \\
\text { shared }\end{array}$ & & Total (N) \\
\hline Iraq & $30 \%$ & $43 \%$ & $22 \%$ & $6 \%$ & $100 \%$ & 196 \\
\hline Syria & $28 \%$ & $38 \%$ & $23 \%$ & $12 \%$ & $100 \%$ & 184 \\
\hline Afghanistan & $25 \%$ & $39 \%$ & $12 \%$ & $24 \%$ & $100 \%$ & 83 \\
\hline Other & $22 \%$ & $45 \%$ & $24 \%$ & $10 \%$ & $100 \%$ & 51 \\
\hline Total & $27 \%$ & $40 \%$ & $21 \%$ & $11 \%$ & $100 \%$ & 514 \\
\hline
\end{tabular}




\section{VIENNA INSTITUTE OF DEMOGRAPHY}

\section{Working Papers}

Barakat, Bilal and Robin Shields, Just Another level? Comparing Quantitative Patterns of Global School and Higher Education Expansion, VID Working Paper $5 / 2016$.

Bloom, David E., Michael Kuhn and Klaus Prettner, Africa's Prospects for Enjoying a Demographic Dividend, VID Working Paper 4/2016.

Frankovic, Ivan, Michael Kuhn and Stefan Wrzaczek, Medical Care within an OLG Economy with Realistic Demography, VID Working Paper 3/2016.

Abel, Guy J., Estimates of Global Bilateral Migration Flows by Gender between 1960 and 2015, VID Working Paper 2/2016.

Testa, Maria Rita, Valeria Bordone, Beata Osiewalska and Vegard Skirbekk, The Relation between Mother's Socio-Economic Status and Daughter's Fertility Intentions in Austria, Italy, Bulgaria, and Norway, VID Working Paper 1/2016.

Hoffmann, Roman and Raya Muttarak, A Tale of Disaster Experience in Two Countries: Does Education Promote Disaster Preparedness in the Philippines and Thailand, VID Working Paper 9/2015.

Klotz, Johannes and Richard Gisser, Mortality Differentials by Religious Denomination in Vienna 1981-2002, VID Working Paper 8/2015.

Steiber, Nadia and Barbara Haas, Overworked or Underemployed? Actual and Preferred Household Employment Patterns in the Context of the Economic Crisis, VID Working Paper 7/2015.

Beaujouan, Eva, Zuzanna Brzozowska and Krystof Zeman, Childlessness Trends in Twentieth-Century Europe: Limited Link to Growing Educational Attainment, VID Working Paper 6/2015.

Abel, Guy, Estimates of Global Bilateral Migration Flows by Gender Between 1960 and 2010, VID Working Paper 5/2015.

Spijker, Jeroen, Alternative Indicators of Population Ageing: An Inventory, VID Working Paper 4/2015.

Kuhn, Michael and Klaus Prettner, Population Structure and Consumption Growth: Evidence from National Transfer Accounts, VID Working Paper 3/2015.

The Vienna Institute of Demography Working Paper Series receives only limited review. Views or opinions expressed herein are entirely those of the authors. 